\title{
A NOAA-USGS Demonstration Flash-Flood and Debris-Flow Early-Warning System
}

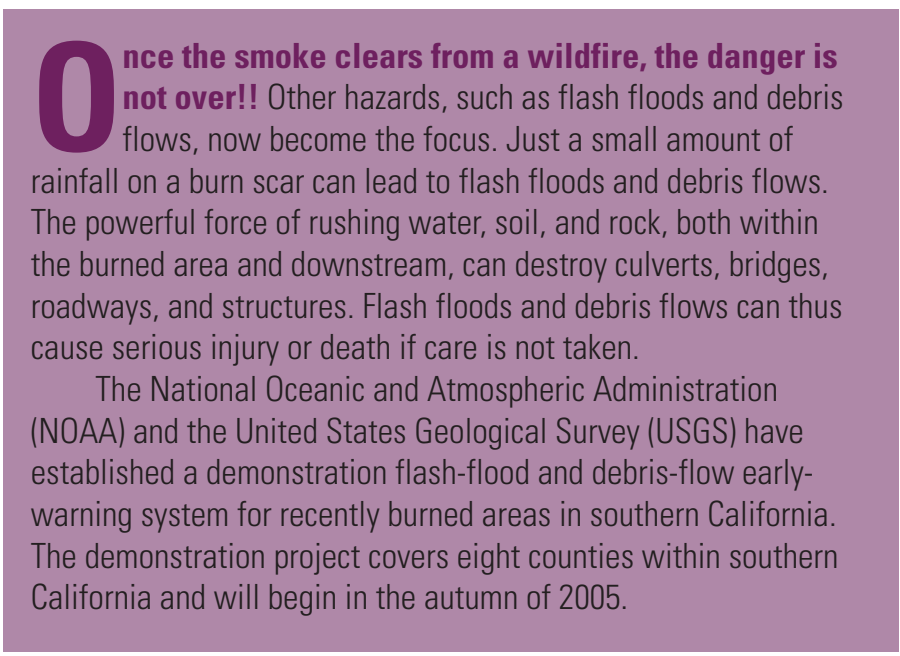

Precipitation Prediction and Monitoring: The National Weather Service (NWS) routinely forecasts and monitors precipitation events. Precipitation forecasts are for both the probability of precipitation occurring and the most likely amount. Forecasts are typically issued twice daily and updated as conditions warrant. Forecasts are derived from a number of numerical and statistical weather models, as well as NWS forecaster expertise. Precipitation monitoring is conducted in real time at the local Weather Forecast Offices using rain gauge networks, NWS doppler radars, and satellite estimates.

Warning System Operation: The demonstration project utilizes the NWS's Flash Flood Monitoring and Prediction (FFMP) system. Comparisons between forecast and observed precipitation and rainfall thresholds allow the FFMP to identify when and where flash floods and debris flows are likely to occur. When precipitation amounts meet or exceed threshold values for a particular drainage basin, the NWS will issue a Watch or a Warning. Advisory Outlooks, Watches, and Warnings are disseminated to emergency management personnel and the public through the NWS Advanced Weather Information Processing System.

Rainfall Thresholds: Warnings and Watches for postfire flash floods and debris flows are based on peak storm duration rainfall thresholds. Such thresholds have been developed

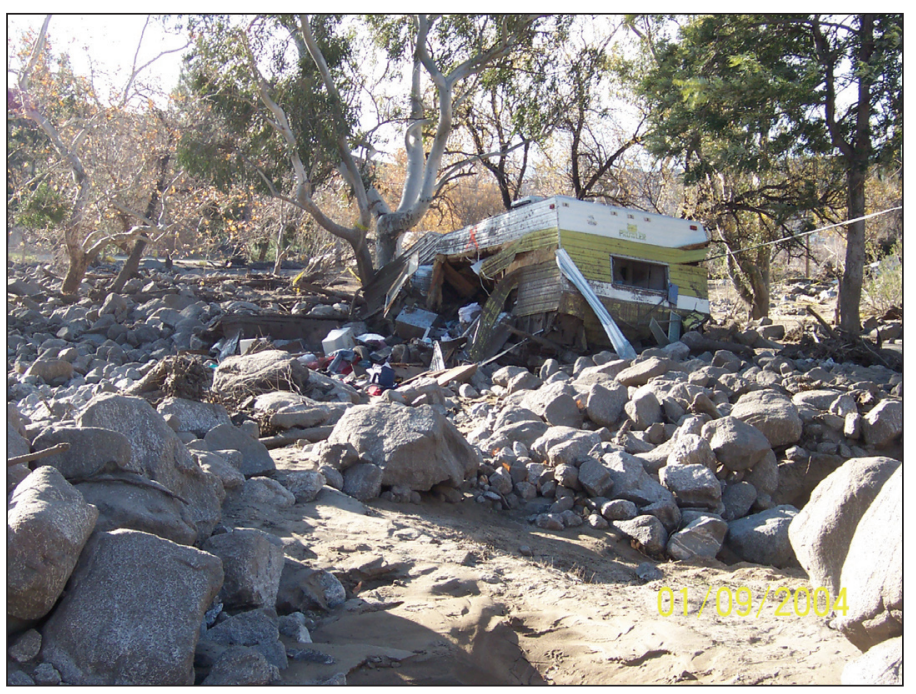

Debris-flow deposits in Cable Canyon in San Bernardino County, California. Cable Canyon was burned during the Grand Prix-Old Fire of 2003 and was the site of debris flows and floods in response to the December 25, 2003 rainstorm. Two people lost their lives at this site.

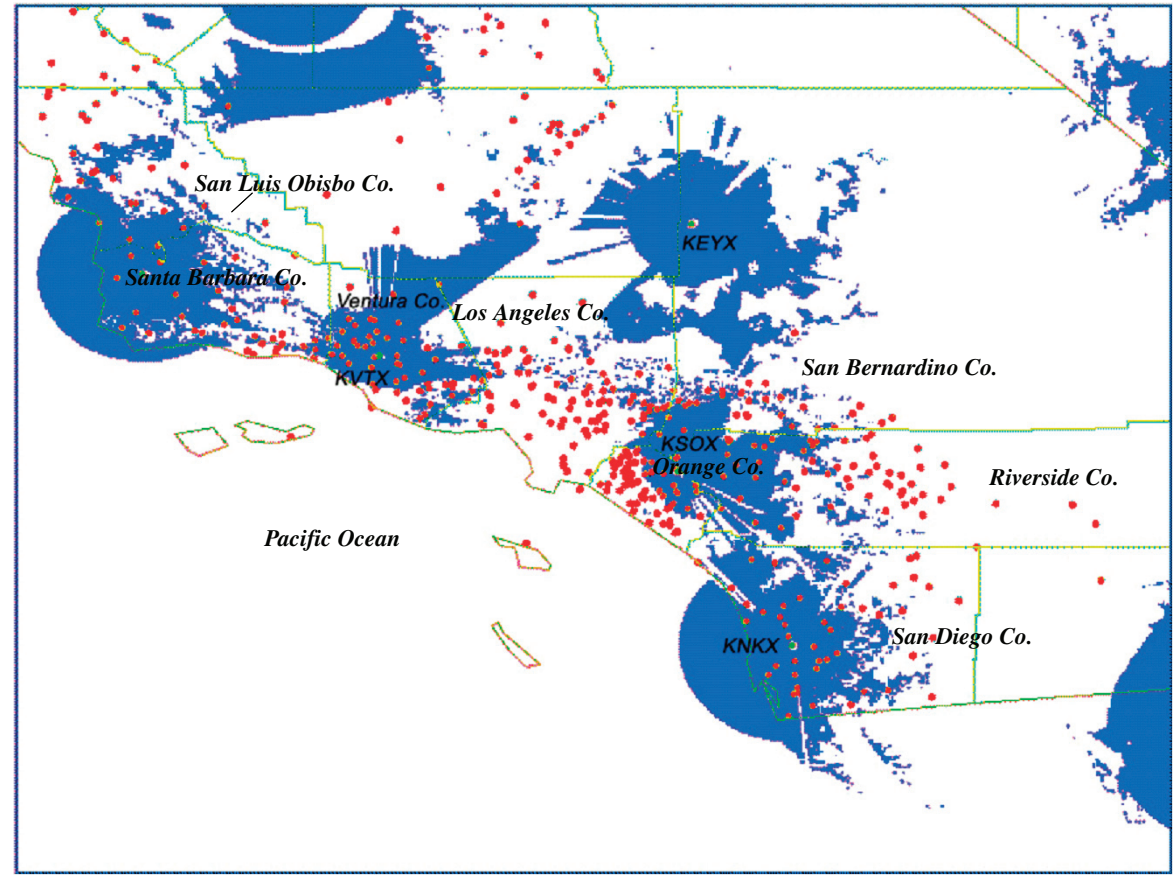

Southern California radar coverage (blue regions) and real-time rain gauge locations (red dots). 
for recently burned areas in southern California by comparing characteristics of storms known to have produced flash floods and debris flows with those that did not. Thresholds have been defined by identifying those combinations of peak storm rainfall and duration that are unique to flash-flood- and debrisflow-producing storms. Postfire threshold conditions change with time as sediment supplies are depleted and vegetation recovers. Therefore, in addition to thresholds that are useful for immediately after a fire, thresholds for the following rainy season have also been developed.

\section{What Can You Do If You Live Near A Recently Burned Area?}

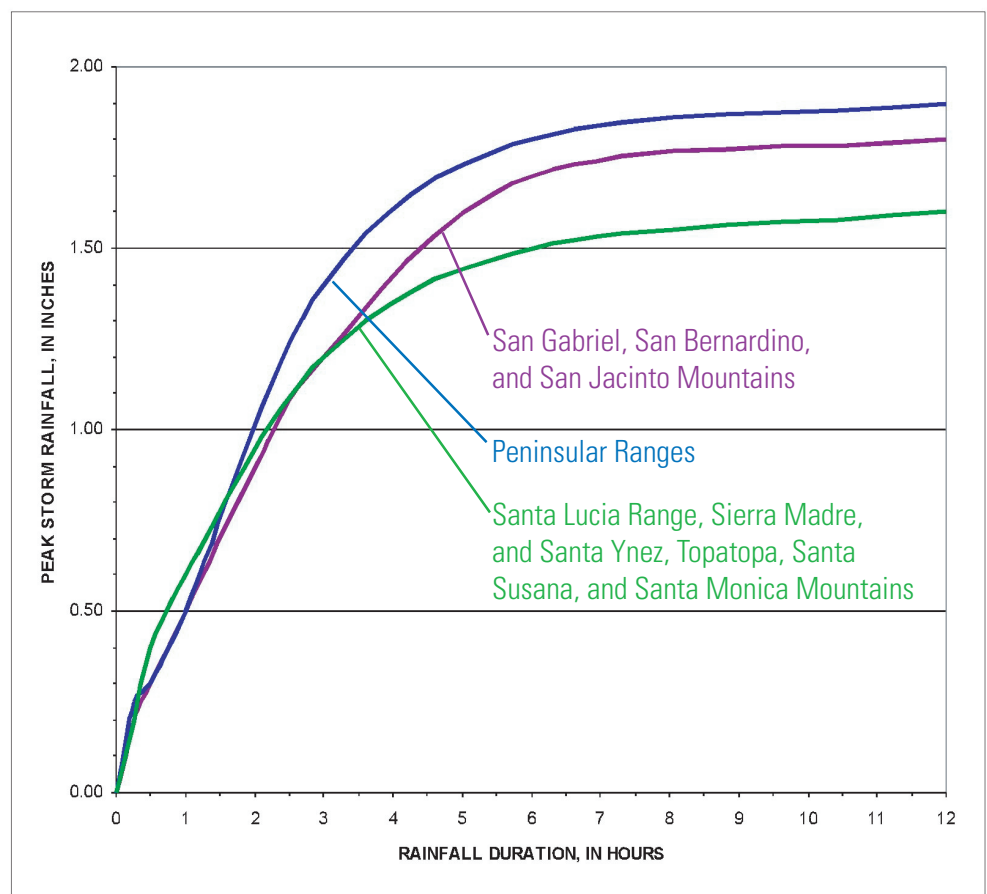

Peak storm rainfall and duration thresholds for recently burned, mountainous areas of southern California. Rainfall conditions above the threshold lines are those likely to trigger debris flows and flash floods from recently burned areas.

Threshold lines delineate a range of rainfall combinations-from short duration, low peak rainfall to longer duration, higher peaks - any of which can result in flashflood or debris-flow activity. Different areas require different thresholds because of variations in surficial materials, vegetation, topography, and prevailing weather patterns.

\section{Prior to Storms:}

1. Watch the patterns of storm-water drainage near your home, and note the places where runoff water converges, increasing flow in channels. These are areas to avoid during a storm.

2. Contact your local authorities to learn about the emergencyresponse and evacuation plans for your area. Develop your own emergency plan for your family or business.

\section{During a Storm:}

1. Stay alert! Many debris-flow and flash-flood fatalities occur when people are sleeping. Listen to the radio for warnings of intense rainfall. NOAA Weather Radio All Hazards tone alert will let you know of hazards in your area. Be aware that intense bursts of rain may be particularly dangerous, especially after longer periods of heavy rainfall.

2. If you are in an area that is susceptible to flooding or debris flow (or has been subject to flooding or debris flows in the past), consider leaving if it is safe to do so. Remember that driving during heavy rainstorms can be hazardous.

3. If you are near a stream or a channel, listen for any unusual sounds that might indicate moving debris, such as trees cracking or boulders knocking together. A trickle of flowing mud or debris may precede larger flows. Be alert for any sudden increases or decreases in water flow and for a change from clear to muddy water. Such changes may indicate debris-flow activity upstream, so be prepared to move quickly. Don’t delay! Save yourself, not your belongings.

4. Keep in mind that rises in water levels during flash floods and debris flows may occur much more rapidly, and may be significantly larger, than those produced when the watershed is not burned.

5. Be particularly alert when driving. Bridges may be washed out, and culverts overtopped. Do not cross flooding streams!! Turn Around, Don't Drown ${ }^{\circledR}$ ! Embankments along roadsides are particularly susceptible to landsliding. Watch the road for collapsed pavement, mud, fallen rocks, and other debris flow and flash-flood dangers.

To see current Outlooks, Watches and Warnings:

http://nhss.cr.usgs.gov

For more information on southern California weather, NOAA's Weather Radio or on post-fire debris flows:

http://www.wrh.noaa.gov/sandiego/

http://www.wrh.noaa.gov/losangeles/

http://www.nws.noaa.gov/nwrl

http://www.warnings.noaa.gov/wxradio.html

http://landslides.usgs.gov/html_files/wildfires/index.html http://landslides.usgs.gov

\section{Also Contact:}

Lynn Highland, U.S. Geological Survey Landslide Information Officer, phone: 1-800-654-4966, e-mail: highland@usgs.gov

Sue Cannon, U.S. Geological Survey Project Chief, e-mail: cannon@usgs.gov

Jayme Laber, National Weather Service Senior Service Hydrologist, e-mail: jayme.laber@noaa.gov

Joe Dandrea, National Weather Service Hydrology Focal Point, San Diego WFO, e-mail: joe.dandrea@noaa.gov

This fact sheet is available on-line at http://pubs.usgs.gov/fs/2005/3104

Publication layout by Margo L. Johnson 